\title{
Myocardial revascularization: factors intervening in the reference and counter-reference in Primary Health Care*
}

\author{
Revascularização miocárdica: fatores interventores na referência \\ e contrarreferência na Atenção Primária à Saúde \\ Revascularización miocárdica: factores interventores en la referencia \\ y contrarreferencia en la Atención Primaria de Salud
}

Kamylla Santos da Cunha ${ }^{1}$, Giovana Dorneles Callegaro Higashi', Alacoque Lorenzini Erdmann ${ }^{1}$, Carolina Kahl' ${ }^{1}$, Cintia Koerich ${ }^{1}$, Betina Hörner Schlindwein Meirelles ${ }^{1}$

How to cite this article:

Cunha KS, Higashi GDC, Erdmann AL, Kahl C, Koerich C, Meirelles BHS. Myocardial revascularization: factors intervening in the reference and counterreference in Primary Health Care. Rev Esc Enferm USP. 2016;50(6):963-970. DOI: http://dx.doi.org/10.1590/S0080-623420160000700013

* Extracted from the research project "Paciente Cardíaco Revascularizado: processo de referência e contrarreferência dos Serviços de Saúde de Santa Catarina”, Universidade Federal de Santa Catarina, 2013-2014.

${ }^{1}$ Universidade Federal de Santa Catarina. Florianópolis, SC, Brazil.
Corresponding author:

Kamylla Santos da Cunha

Centro de Ciências da Saúde -

Campus Universitário - Trindade

CEP 88040-900 - Florianópolis, SC, Brazil

kamyllascunha@gmail.com

\begin{abstract}
Objective: Understanding the factors that influence the reference and counter-reference process of people indicated/submitted to Myocardial Revascularization surgery in the Primary Health Care scenario. Method: A qualitative research anchored in the Grounded Theory, totaling 41 participants subdivided into three groups (patients, health professionals and managers) in the Metropolitan and West Region of Santa Catarina. Results: Two categories elucidate the intervening factors found, contrasting the potentialities and obstacles in (creating) the bond between people affected by cardiovascular diseases and primary health care for the reference process, highlighting weaknesses in the primary health care services provided, with failures in the counter-reference for people submitted to myocardial revascularization surgery. Conclusion: Strengthening the potentialities presented in this study is essential for the reference process of people affected by Cardiovascular Disease, as well as strategic actions focused on solving the evidenced obstacles which contribute to deficiencies in the referral and counter-referral process, thus impeding integral care in the health care network.
\end{abstract}

\section{DESCRIPTORS}

Myocardial Revascularization; Integrality in Health; Referral and Consultation; Primary Care Nursing; Primary Health Care. 


\section{INTRODUCTION}

Cardiovascular Diseases (CVD) are among the leading causes of death worldwide, and it is estimated that there will be a significant increase from 16.7 million deaths recorded in 2002 to 23.3 million in 2030 ${ }^{(1)}$. In Brazil, CVD are at the top of mortality causes; in 2013, 339,672 deaths were recorded due to circulatory system diseases, with 85,939 referring to Acute Myocardial Infarction (AMI) ${ }^{(2)}$.

Myocardial Revascularization Surgery (MRS) has been established as one of the indicated treatments for AMI, showing results in relieving angina, improving exercise tolerance and increasing life expectancy and quality of life ${ }^{(3)}$. Given the complexity of the pre and post-operative MRS process, careful attention by health professionals is required. This is especially true for nurses due to their specificity of being involved in the care attention at all stages of the health-disease process and inserted in the various Health Care Network (HCN) (Rede de Atenção à Saúde - RAS) scenarios, and with a holistic view of the patient considering their particularities, needs and demands in the search for better surgical experience results ${ }^{(4)}$.

It can be said that one of the causes of increased AMI incidence in developing countries is related to the difficulty of healthcare access, especially for CVD preventive measures ${ }^{(5)}$. Thus, actions to promote and protect the health of people affected by CVD in Primary Health Care (PHC) (Atenção Primária à Saúde-APS) are fundamental for preventing acute events, including: the control of systemic arterial hypertension, dyslipidemia and smoking; adherence to life practices considered healthy, such as adequate diet and regular physical exercise; and adherence to drug treatment ${ }^{(5)}$.

In this sense, through high complexity and low density technologies, $\mathrm{PHC}$ is characterized by a set of individual and collective actions aimed at health promotion and protection, disease prevention, diagnosis, treatment, rehabilitation and health maintenance ${ }^{(6)}$. It is defined as a structuring of the health system, organizing the $\mathrm{HCN}$ and coordinating care, in addition to providing case management from the access and longitudinality/continuity of the care offered ${ }^{(7)}$.

A recent study carried out in southeastern Brazil aiming to evaluate the service performed by the Family Health Strategy (FHS) (Estratégia Saúde da Família - ESF) units, and based on social representations of the interviewees regarding exclusive PHC dimensions, points out difficulties for the full development of integrality and care coordination characteristics, highlighting an absence of an integrated and regionalized network for reference and counter-reference ${ }^{(8)}$. The reference and counter-reference process aims to enable information and communication exchange between the services provided at the different healthcare points of the network, thereby preventing duplicated efforts with the purpose of improving the care quality and achieving effective comprehensiveness in healthcare ${ }^{(9)}$.

Aiming to respect the principles and guidelines proposed by the Unified Health System (Sistema Unico de Saúde - SUS), and given the importance of a structured network to provide assistance to people affected by cardiovascular diseases, it is relevant for nurses and other healthcare professionals and managers to analyze the route of people affected by CVD indicated/submitted to MRS in the SUS healthcare network. This is important in order to design strategies for monitoring the health of these people, and considering the high incidence of morbidity and mortality due to circulatory system diseases and their consequent high cost to the healthcare system. Thus, we ask: What factors influence the reference and counter-reference process of people indicated/submitted to MRS in the Primary Health Care (PHC) scenario?

The objective of this study was to understand the factors that influence the reference and counter-reference process of people indicated/submitted to Myocardial Revascularization Surgery (MRS) in the Primary Health Care (PHC) scenario.

\section{METHOD}

This is a qualitative study with a methodological approach based on the Grounded Theory (GT), which seeks to understand social phenomena from the meanings of the relationships and interactions between the subjects. In GT, the data collection and data analysis process occur concomitantly, enabling the researchers to further deepen the research problem by identifying, developing and relating concepts $^{(10)}$. Data were collected from March to June 2014, in two large municipalities in the state of Santa Catarina (one in the metropolitan region and the other in the western part of the state), through open and individual interviews recorded via digital audio. The sample consisted of 41 participants (25 located in the metropolitan region and 16 in the western region), who were then distributed among three sample groups ${ }^{(10)}$.

The first sample group consisted of patients identified from inpatient hospital data who met the following inclusion criteria: adults of both genders who had undergone MRS at least 6 months prior, and who were already at home. In this group, 14 patients from both municipalities were interviewed using the initial question: Tell me about your health followup in the PHC before and after your MRS. The patients' speech emphasized the performance of health professionals during their course in the HCN. The second group was formed based on data analysis from the first sample group.

In order to compose the second sample group, the inclusion criteria were health professionals linked to the $\mathrm{PHC}$ network who had been working in the health unit or specialized referral center for at least six months. This group was formed by 21 professionals from both municipalities, being eight nurses, six physicians and seven community health agents. The initial question for this group was: How do you experience the reference and counter-reference process of people submitted to MRS in the PHC scenario?

Based on the emphasis given by health professionals to the regulatory system, we chose to deepen the information collection in order to achieve greater theoretical consistency. To that end, the third sample group consisted of six professionals linked to the municipality's regulation system (SISREG) of the metropolitan region, consisting of two physicians and one administrative professional, and one physician and two nurses from the Reference Center in Municipal Health (Central de Referência em Saúde 
Municipal - CRESM) in the western region of the state, who were interviewed using the following guiding question: How does municipal regulation contribute to the reference and counter-reference process of people submitted to MRS?

The exclusion criteria adopted for this study were: patients under 18 years of age or those without the clinical condition to respond to the interview, and professionals on leave for any reason during the period of data collection.

There was a simultaneous involvement in data collection and analysis. Theoretical saturation was obtained from information repetition about the phenomenon, absence of new elements relevant to the analysis and consolidation of categories and subcategories in their properties and dimensions. The analysis process followed the three codings presented by the method, open, axial and selective codings. The codes were grouped, and their groupings gave rise to the categories and subcategories as defined and developed in terms of their properties and dimensions ${ }^{(10)}$. NVIVO ${ }^{\circledR}$ software was used for sorting and organizing data in the coding process. The analytical process was constructed according to the Paradigmatic Model, constituted by five components (context, cause, intervening condition, strategies and consequences) which explain the phenomenon ${ }^{(10)}$.

The present study is part of a larger project entitled 'Revascularized Cardiac Patient: the reference and counter-referral process of the Santa Catarina Health Services' (Paciente Cardiaco Revascularizado: processo de referência e contrarreferência dos Serviços de Saúde de Santa Catarina) which presents the phenomenon 'High complexity care is emerging as the reference for people submitted to Myocardial Revascularization due to the fragility of Basic Healthcare in the follow-up and articulation with other levels of care in the SUS.' Given the importance and relevance of the Intervening Condition analytical component for understanding the phenomenon, we chose to broaden and deepen this discussion.

The development of this study complied with the ethical precepts of Resolution No. 466/12 of the National Health Council. The project was approved by the Research Ethics Committee with Human Beings of the Universidade Federal de Santa Catarina (CEPSH/UFSC), under protocol number 120.184 . In order to guarantee the confidentiality and anonymity of the participants, the letter $\mathrm{E}$ is followed by the number corresponding to the order of the interviews to designate them (E1, E2, E3...) and also indicating the sample group - first group (G1), second group (G2), third group (G3) - as follows: (E1G1); (E1G2); (E1G3).

\section{RESULTS}

Two categories emerged from the data analytical process of the intervening component, entitled: Potentialities and barriers in the bond between people with cardiovascular disease and Primary Health Care in the reference process and Weaknesses in Primary Health Care services with failures in the counter-reference process of revascularized patients. Such categories elucidate the intervening factors in the reference and counter-reference processes experienced by individuals indicated/submitted to MRS in the SUS while going through the Healthcare System in the state of Santa Catarina.
The first category reveals the use of $\mathrm{PHC}$ among potentialities for obtaining medications, access to consultations and examinations as facilitators to strengthen the bond between people affected by CVD and PHC, which is a favorable factor to the reference process of these people in the $\mathrm{HCN}$ in both municipalities.

In this case, my wife and I are fans of the basic health clinic, sometimes I tell her, "Oh, I have to see the doctor." She goes over there (to the health clinic), she is very diligent. Even my continuous medications, I get it all at the health clinic, she goes there with my card and gets her (medicine) and mine (E4G1).

Regarding access to consultations in the metropolitan area of the state, part of the health professionals' agenda is allocated to spontaneous demand consultations where the patient arrives at the unit and waits to be seen; and the other part of their agenda is allocated to scheduled demand, meaning pre-scheduled consultations. This division is reported as a facilitator for patient access, since when they cannot make an appointment, they end up being attended due to spontaneous demand.

Usually they arrive (at the basic health unit) with a demand for a different reason, for example, they came due to an increase in pressure (arterial), they had the surgery and now they are receiving follow-up. They go through spontaneous demand and then they are evaluated by the team (E15G2).

The Emergency Care Unit (Unidade de Pronto Atendimento - UPA) in the metropolitan region of the state is used as a reference for PHC and patients with acute cases and those with the impossibility of being solved by the primary care. Some patients report seeking the Basic Health Unit (Unidade Básica de Saúde - UBS) first in the face of an acute event, which characterizes the trust established between the health team and these users.

It does happen that they (patients) will come here (PHC) knowing they could have gone straight to the hospital, so we do all the clinical examining of the patient, and if it is really the case of an acute emergency (...) we refer them to the UPA or to the hospital (E16G2).

The importance of managing care practices in patients affected by CVD in the PHC by the nurse is evidenced through meetings that aim to deliberate health actions and improve access to PHC users.

We have team meetings every week, where we discuss the most difficult cases. Nurses attend together to also work on the issue of treatment adherence (E21G2).

There is a deficiency in user's guidelines and welcoming at the PHC level among obstacles related to access of patients affected by CVD, which consequently interferes in the reference process. This fact is pointed out as a consequence from the lack of professionals in PHC, and the need for improved training of the working professionals on the problems of cardiovascular diseases and repercussions in the lives of users/patients. In this context, the insufficient number of Community Health Agents (CHA) (Agentes Comunitários de Saúde-ACS) in the Family Health Strategy (FHS) teams interfere in the bond between users and the 
health team, since communication between PHC and the coverage area is impaired.

The community agent is the bridge between the patient and the team, usually they bring cases that do not reach us, they detect other issues (...) I think they are essential (E21G2).

In the municipality in the western region, one factor that impairs access to $\mathrm{PHC}$ is the waiting list for routine medical appointments, considering that $\mathrm{PHC}$ professionals' agendas are restricted to scheduled consultations, and which are scheduled for another time with limited vacancies and delays in referencing the patient to medium complexity specialists to define the diagnosis when necessary.

They come here to us, but they are not attended to at that time. They have to schedule the appointment. Because here we can only see them at a scheduled date and time, and this sometimes ends up delaying the service (E33G2).

Excessive waiting time to perform cardiac surgery has received criticism from both regions of the state. Patients remain on the waiting list for long periods, and can wait up to a year. While waiting for heart surgery, patients report that they remained at home, following health guidelines and maintaining a bond with the PHC through consultations, renewing prescriptions and picking up medications. However, others are evaluated by medium complexity specialists or are hospitalized while waiting for the MRS due to disease repercussions, considering that the MRS is regulated by the institution's own high complexity care at the intrahospital level. This factor can lead to worsening of the disease or the repercussion of new cardiac events.

They wait to be called for the surgery and end up getting continuous and controlled medications here, and if they need any exams they ask us (E16G2).

I waited for almost three years to undergo myocardial revascularization surgery and, while I waited, I ended up having another beart attack (between the first event and surgery) (E10G1).

Thus, the delay in cardiac surgery in both regions of the state is the main factor that defers CVD patients to seeking private care in order to speed up the diagnostic definition process and health care, often interrupting monitoring by the PHC team.

Another factor mentioned by the participants as an obstacle to the reference process concerns the information management in SISREG. This is a national computerized system for managing consultations and examinations with specialists and used in the state of Santa Catarina. Participants reported difficulty in completing the data by introducing the patient on the waiting list for specialist consultations and diagnostic tests, which makes it difficult to give priority to patients with greater severity. We emphasize that correct registration in SISREG is essential for the patient to be served by the priority criterion established by the regulators.

The doctor is the one who requests it (the referral) through an observation note, when it is handwritten it becomes much more difficult for those who are in the scheduling to decipher (the hand-writing), so it should always be priority to have it digitalized (the referral request). They (the scheduling team) write it down, and the more data they enter, the better it is for the regulator to evaluate, since they (the regulators) are not with the patient, they will evaluate them according to what has been evaluated by the doctor and what is in the system (E36G3).

In short, some managerial actions used by the nurse and health team within the PHC are responsible for favoring access to PHC, creating a bond between the health team and the user, and facilitating the process of early CVD identification and reference to the HCN. On the other hand, municipal management obstacles were cited as impediments that end up preventing the reference process from occurring.

The second category, entitled Weaknesses in Primary Health Care services with failures in the counter-reference process of revascularized patients points to similarities regarding the counter-reference process of patients submitted to MRS in both municipalities (metropolitan and western regions).

The main weakness of the counter-reference process of patients submitted to MRS is in following-up this patient by PHC due to communication failures between PHC and high complexity services after surgery. This fact is related to the weak understanding of health professionals regarding the reference and counter-reference process in the HCN of SUS, negatively affecting the guarantee of health care comprehensives for this patient.

The lack of communication between reference hospital services and basic care is what we see the most. We don't know how the hospital service works, and I believe this service also doesn't know how basic care works. I think maybe it's a lack of information, perhaps a working flow of these services is missing (reference and counter-reference), a functioning standard. (E18G2).

In the metropolitan area, many patients are advised to continue their healthcare monitoring at the outpatient clinic of the hospital where the surgery was performed. We emphasize the importance of the hospital institution to follow-up on patient's monitoring after surgery, considering aspects such as cardiac rehabilitation and the need for lifestyle changes, due to the lack of structure and preparation of PHC professionals to monitor this patient.

The only monitoring that I have is at the hospital every 15 days (E5G1).

During the first 30 days, I went to the hospital for check-ups, as to the guidelines (by the health professional) (E4G1).

Among the means available for communication among professionals at the $\mathrm{HCN}$ is the electronic medical record present in both municipalities, which contains information about the patient, and can be shared between primary and medium complexity care. However, high complexity care uses a computer system which is not integrated to the system used in PHC, interrupting the information flow and weakening the counter-referencing process. High complexity is managed by the state government, and primary care and medium complexity by the municipalities. Thus, the participants affirm that not using a discharge summary or discharge pass impairs the counter-referral process, directly affecting patient care. 
Because we have the electronic medical record (primary level), we have access to the cardiologist's records (at the secondary level). The patient did a procedure at the cardiologist and I want to know what it is, so I access the record and I can see their history. There is no record of when they did the surgery, only if they returned to the cardiologist and their return is registered (E29G2).

The reduced number of CHA in FHS teams is also evidenced in the counter-reference process, negatively affecting the post-surgery follow-up of these patients, since the need for home visits is commonly linked to this. In this way, most of the time UBS does not take notice of the patient who underwent the surgery, as the bond between PHC and the community is compromised. The lack of integration between the service and the community impairs quality and comprehensive patient care pre- and post-MRS, which can result in new cardiac events and possible new MRSs. Thus, we can conclude that patients' counter-reference after MRS seems to be fragile, with the absence of a formal route to be followed after hospital discharge, often considering the non-reference of these patients who seek high complexity care as a gateway into the system.

\section{DISCUSSION}

The findings of this study have evidenced an excess in waiting time for a scheduled PHC consultation and referral for specialized consultation in the metropolitan and western regions of the state as impediments to access or create a bond, and consequently to the patient's reference process for specialized HCN services. A study carried out in the northeast of Brazil with the objective of evaluating users' perceptions regarding the quality of care at the UBS points to users' dissatisfaction with the waiting time for appointments and scheduling specialized consultations, highlighting difficulties related to service being organized in a timely and effective manner ${ }^{(11)}$.

Corroborating the above, a study aiming to investigate the most valued dimensions by users in PHC highlights difficulties in scheduling fixed appointments, obtaining examinations and the prolonged waiting time for referrals to specialized consultations ${ }^{(12)}$. By concurrently waiting for the PHC services, there is evidence of a movement by the population in searching for alternative health access, with an option of using complementary services such as private health plans ${ }^{(13)}$.

Spontaneous demand is cited as a facilitator in accessing PHC and in patient referral to health services. Accepting/ attending spontaneous demand directs organizational and functional changes for those who seek the health service, being one of the first actions that the team's professionals perform through active listening with answers to the presented needs, providing problem solving or guidance in searching for solutions within the PHC or other SUS services $^{(14)}$. A study on the time standards of nursing interventions/activities in FHS units showed that nursing consultations, home visits and attending to spontaneous demand were the most frequent interventions performed by nurses in this setting, being considered practices which can enhance user access to the service, humanize service and function as reorganizers of the work process ${ }^{(15)}$.
Within the scope of PHC, the nurse has an important managerial assignment in directing/communicating with the team and forming strategic actions to improve access and monitoring of patients indicated/submitted to MRS. They carry out specific technical activities within their competence (both administrative and educational), and through the bond with users they concentrate efforts to plan care actions with other PHC professionals in a singular and multifaceted manner for effective care ${ }^{(16)}$.

With regard to patient waiting time for MRS, this issue has been nationally and internationally debated. In the United States, intervention for MRS in most patients occurs within approximately 72 hours, while patients in the United Kingdom wait for approximately three months ${ }^{(17)}$. According to the Organization for Economic Co-operation and Development (OECD), the waiting time for MRS should include the waiting time for the first consultation, diagnostic tests and waiting time for the surgery, considering that the longer the waiting time, the higher the mortality incidence in this period ${ }^{(18)}$.

The bond between PHC and user is preferably established through follow-up consultations at the reference UBS, prescription renewal, and medication purchase. Access to good living conditions and health technologies which make it possible to improve and prolong life is understood by patients as a way of maintaining a bond with PHC, while also understanding that the bond is established when they can perform the consultations, complementary exams and have access to medicine free of $\operatorname{cost}^{(19)}$. The bond between nurse and user is related to interpersonal communication and interaction between both in a process that results in user satisfaction, with this being one of the main indicators of quality in the health area ${ }^{(20)}$.

More evidence of the bond between the user and the health professional is related to the referral of a patient in PHC to the UPA when facing an acute incident, considering that they seek PHC as a gateway. UPAs can be considered an entrance for emergency and emergency services and are available for patients referred from the UBS ${ }^{(21)}$.

Regarding counter-reference, the results converge with the findings of other studies, pointing to the inexistence or weakness of the patient's return to $\mathrm{PHC}^{(22-23)}$. These findings negatively affect the network's functionality, since they represent a discontinuous process of healthcare that disconnects the flow of care $^{(9)}$. The HCN aims at continuous and comprehensive care for the population, establishing horizontal relations between the different network attention points, where each service has defined characteristics and functions according to the different technological densities ${ }^{(6,24)}$.

The complexity diversity of $\mathrm{HCN}$ and the variety of specialists can represent difficulties in counter-reference, since these professionals do not see the importance of PHC and the professionals who work there ${ }^{(22)}$. After hospital discharge and in a stable condition, the patient can receive care continuity in $\mathrm{PHC}$, since $\mathrm{HCN}$ recommends that patient monitoring after being referred to another sector of greater complexity be concomitant with other sectors ${ }^{(23)}$.

A study of patients submitted to MRS in the south of Brazil presented the difficulty of accessing the PHC 
to schedule medical consultations and obtain medication for continuous health treatment after hospital discharge as being the main problem. Also, it was observed that the patients continued to be attended at the outpatient clinic of the hospital due to disorganization in the $\mathrm{PHC}^{(25)}$. Thus, improving PHC professionals is necessary, considering that low effectiveness in this sector is a factor which increases the number of referrals, increasing the demand in other parts of the network ${ }^{(24)}$, thus affecting counter-reference. Another factor that interferes with PHC's performance on this demand is the lack of professionals who make up the FHS teams, emphasizing a lack of $\mathrm{CHAs}^{(26)}$.

A supplementary tool in the reference and counterreference process consists of the electronic medical record, being present in both municipalities of the study. The support from a medical record on the patient leads to improved PHC, communication between professionals and information sharing between sectors ${ }^{(27)}$. Even with technological advances and a computerized system that connects $\mathrm{PHC}$ and medium complexity healthcare, an expanded system which integrates the $\mathrm{HCN}$ points is necessary. A study carried out in Montes Claros (state of Minas Gerais) resulted in presenting an absence of a single electronic medical record system having access at all points of the network, thereby affecting healthcare continuity ${ }^{(28)}$.

Also, with regard to information systems, SISREG is an important instrument for managing flows in the SUS. It is a means for digital scheduling of consultations and examinations with specialists, and depends on correct completion in requesting the reference. Thus, we reinforce the importance of continuous training and improving of professionals who work with SISREG in order to guarantee equity to users ${ }^{(29)}$.

\section{CONCLUSION}

The study revealed intervening factors in the reference and counter-reference process of people indicated/submitted to MRS in Santa Catarina, Brazil. Managerial actions that favor the bond between user and PHC and access through spontaneous demand in the metropolitan region of the state are evidenced in the reference system. Excessive waiting time for the scheduled PHC consultations, consultations with specialists and MRS, the lack or need of professional improvement and inadequate use of technologies and systems are weaknesses in the reference system. In the counterreference system, the weaknesses were a lack of communication between PHC and the high complexity care network, emphasizing the inexistence of integrated electronic record systems, incipient knowledge of the professionals regarding the flow of care in the $\mathrm{HCN}$, and the insufficient number of CHAs in the composition of the FHS teams.

We emphasize that the obstacles pointed out in this study contribute to pointing out deficiencies in the reference and counter-reference process which make access to primary and specialized health services difficult, impede the user's bond with the PHC before and after MRS and the need for enhancing technologies that facilitate information/ communication and the continuity of comprehensive care across all points of the HCN to strengthen the SUS.

This study is limited to understanding the reference and counter-reference process from the PHC perspective only. Thus, given the complexity of this process involving care for people affected by CVD with the need for surgical intervention in SUS, we emphasize the need for studies that broaden understanding and provide support for strengthening the reference and counter-reference processes for patients affected by CVD in the HCN.

\section{RESUMO}

Objetivo: Compreender os fatores que influenciam o processo de referência e contrarreferência da pessoa com indicação/submetida à Cirurgia de Revascularização Miocárdica no cenário da Atenção Primária à Saúde. Método: Pesquisa qualitativa ancorada na Teoria Fundamentada nos Dados, totalizando 41 participantes subdivididos em três grupos (pacientes, profissionais de saúde e gestores) na Região Metropolitana e Região Oeste de Santa Catarina. Resultados: Duas categorias elucidam os fatores interventores encontrados, Contrastando as potencialidades e entraves no vínculo da pessoa acometida por doenças cardiovasculares com a atenção primária à saúde para o processo de referência e Destacando fragilidades nos serviços disponibilizados na atenção primária à saúde, com insucessos da contrarreferência da pessoa submetida à cirurgia de revascularização miocárdica. Conclusão: Torna-se essencial o fortalecimento das potencialidades apresentadas neste estudo para o processo de referência da pessoa acometida por Doença Cardiovascular, assim como ações estratégicas com foco na resolução dos entraves apontados e que contribuem para a deficiência do processo de referência e contrarreferência, dificultando a integralidade do cuidado na rede de atenção à saúde.

\section{DESCRITORES}

Revascularização Miocárdica; Integralidade em Saúde; Referência e Consulta; Enfermagem de Atenção Primária; Atenção Primária à Saúde.

\section{RESUMEN}

Objetivo: Comprender los factores que influencian el proceso de referencia y contrarreferencia de la persona con indicación/sometida a la Cirugía de Revascularización Miocárdica en el marco de la Atención Primaria de Salud. Método: Investigación cualitativa anclada en la Teoría Fundamentada en los Dados, totalizando 41 participantes subdivididos en tres grupos (pacientes, profesionales sanitarios y gestores) en la Región Metropolitana y Región Oeste de Santa Catarina. Resultados: Dos categorías elucidan los factores interventores encontrados, contrastando las potencialidades y obstáculos al vínculo de la persona que sufre de enfermedades cardiovasculares con la atención primaria de salud para el proceso de referencia y destacando fragilidades en los servicios facilitados en la atención primaria de salud, con fracasos de la contrarreferencia de la persona sometida a la cirugía de revascularización miocárdica. Conclusión: Se hace esencial el fortalecimiento de las potencialidades presentadas en este estudio para el proceso de referencia de la persona que sufre de Enfermedad Cardiovascular, así como acciones estratégicas con enfoque en la resolución de los obstáculos señalados y que contribuyen para la deficiencia del proceso de referencia y contrarreferencia, dificultando la integralidad del cuidado en la red de atención sanitaria. 


\section{DESCRIPTORES}

Revascularización Miocárdica; Integralidad en Salud; Remisión y Consulta; Enfermería de Atención Primaria; Atención Primaria de Salud.

\section{REFERENCES}

1. Furuya RK, Mata LR, Veras VS, Appoloni AH, Dantas RA, Silveira RC, et al. Original research: telephone follow-up for patients after myocardial revascularization: a systematic review. Am J Nurs. 2013;113(5):28-31.

2. Brasil. Ministério da Saúde. DATASUS. Sistema de Informações Hospitalares. Internações e valor total de internações segundo capítulo CID-10 [Internet]. Brasília; 2013 [citado 2016 abr 4]. Disponível em: http://www.datasus.gov.br

3. Crouse SB, Kitko LA. Outcomes of coronary artery interventions: comparing coronary artery bypass surgery and percutaneous coronary intervention in patients with unprotected left main stenosis. J Am Assoc Nurse Pract. 2014;26(2):91-101.

4. Borges DL, Nina VJS, Lima RO, Costa MAG, Baldez TEP, Santos NP, et al. Características clínicas e demográficas de pacientes submetidos à revascularização do miocárdio em um hospital universitário. Rev Pesq Saúde. 2013;14(3):171-4.

5. Andrade JP, Mattos LAP, Carvalho AC, Machado CA, Oliveira GMM. National physician qualification program in cardiovascular disease prevention and integral care. Arq Bras Cardiol. 2013;100(3):203-21.

6. Tanaka OY. Avaliação da atenção básica em saúde: uma nova proposta. Saúde Soc. 2011;20(4):927-34.

7. Conselho Nacional de Secretarias Municipais de Saúde (CONASEMS). A Atenção Básica que queremos [Internet]. Brasília: CONASEMS; 2011 [citado 2016 abr. 11] Disponível em: http://www.cosemsam.org.br/wp-content/uploads/2016/04/a-atencao-basica-que-queremos.pdf

8. Gomes KO, Cotta RMM, Araújo RMA, Cherchiglia ML, Martins TCP. Atenção primária à saúde - a "menina dos olhos" do SUS: sobre as representações sociais dos protagonistas do Sistema Único de Saúde. Ciênc Saúde Coletiva. 2011;18 Supl.:S881-92.

9. Brito MCC, Freitas CASL, Silva MJ. Elderly health care: the referral and counter-referral system in health services. J Res Fundam Care Online [Internet]. 2013 [cited 2016 Apr 13];6(3): 1128-38. Available from: http://www.seer.unirio.br/index.php/cuidadofundamental/ article/view/2878/pdf_1368

10. Strauss A, Corbin J. Pesquisa qualitativa: técnicas e procedimentos para o desenvolvimento de teoria fundamentada. $2^{\text {a }}$ ed. Porto Alegre: Artmed; 2008.

11. Santiago RF, Mendes ACG, Miranda GMD, Duarte PO, Furtado BMASM, Souza WV. Qualidade do atendimento nas Unidades de Saúde da Família no município de Recife: a percepção dos usuários. Ciênc Saúde Coletiva. 2013;18(1):35-44.

12. Moraes VD, Campos CEA, Brandão AL. Estudo sobre dimensões da avaliação da estratégia saúde da família pela perspectiva do usuário. Physis. 2014;24(1):127-46.

13. Mendes JDV, Osiano VLRO. Consultas médicas de Atenção Básica nas RRAS do Estado de São Paulo. GAIS Informa [Internet]. 2012 [citado 2016 abr. 13];16(4):1-19. Disponível em: http://portal.saude.sp.gov.br/resources/ses/perfil/profissional-da-saude/destaques//gais_jornal_16.pdf

14. Beraldi DC, Souto BGA. A demanda do acolhimento em uma unidade de saúde da família em São Carlos, São Paulo. Arq Bras Ciênc Saúde. 2011;36(1):10-7

15. Bonfim D, Fugulin FMT, Laus AM, Peduzzi M, Gaidzinski RR. Time standards of nursing in the Family Health Strategy: an observational study. Rev Esc Enferm USP. 2016;50(1):118-26. DOI: http://dx.doi.org/10.1590/S0080-623420160000100016

16. Souza MG, Teixeira MED, Nogueira EA. Percepções de enfermeiros sobre seu trabalho na Estratégia Saúde da Família. Texto Contexto Enferm. 2013;22(3):772-9.

17. Amado J, Bento D, Silva D, Chin J, Marques N, Gago P, Alterações nas redes de referenciação de doentes para cirurgia cardiotorácica: as razões económicas serão destituídas de custos? Rev Port Cardiol. 2015;34(10):575-81.

18. Organization for Economic Cooperation and Development (OECD). Health at a Glance 2013: OECD indicators [Internet]. 2013 [cited 2016 Apr 13]. Available from: https://www.oecd.org/els/health-systems/Health-at-a-Glance-2013.pdf

19. Franco AF, Hino P, Nichiata LYI, Bertolozzi MR. A compreensão das necessidades de saúde segundo usuários de um serviço de saúde: subsídios para a enfermagem. Esc Anna Nery. 2012;16(1):157-62.

20. Tajero LM. The mediating role of the nurse-patient dyad bonding in bringing about patient satisfaction. J Adv Nurs. 2012;68(5):994-1002.

21. Uchimura LYT, Viana ALA, Silva HP, Ibanez N. Unidades de Pronto Atendimento (UPAs): características da gestão às redes de atenção no Paraná. Saúde Deb. 2015;39(107):972-83.

22. Costa SM, Ferreira A, Xavier LR, Guerra PNS, Rodrigues CAQ. Referência e contrarreferência na saúde da família: percepção dos profissionais de saúde. Rev APS. 2013;16(3):287-93.

23. Corrêa ACP, Dói HY. Counter-referral of women who experienced high-risk pregnancy to family health units in Cuiabá. Ciênc Cuid Saúde. 2014;13(1):104-10.

24. Arruda C, Lopes SGR, Koerich MHAL, Winck DR, Meirelles BHS, Mello ALSF. Health care networks under the light of the complexity theory. Esc Anna Nery 2015;19(1):169-73.

25. Lanzoni GMM, Higashi GDC, Koerich C, Erdmann AL, Baggio MA. Fatores que influenciam o processo de viver a revascularização cardíaca. Texto Contexto Enferm. 2015;24(1):270-278.

26. Campos RTO, Ferrer AL, Gama CAP, Campos GWS, Trapé TL, Dantas DV. Avaliação da qualidade do acesso na atenção primária de uma grande cidade brasileira na perspectiva dos usuários. Saúde Deb. 2014;38(n.esp):252-64. 
27. Brasil AMFE, Medeiros CRG, Saldanha OMFL. Estratégia Saúde da Família: análise dos registros em prontuários. Cad Pedagógico [Internet]. 2015 [citado 2016 abr. 22];12(1):265-76. Disponível em: http://www.univates.br/revistas/index.php/cadped/article/view/950

28. Gonçalves JPP, Batista LR, Carvalho LM, Oliveira MP, Moreira KS, Leite MTS. Prontuário eletrônico: uma ferramenta que pode contribuir para a integração das Redes de Atenção à Saúde. Saúde Deb. 2013;37(96):43-50.

29. Pinto JR, Carneiro, MGD. Avaliação do agendamento online de consultas médicas especializadas através da central de regulação do SUS. Saúde Colet. 2012;9(58):123-8.

Financial support: Fundação de Amparo à Pesquisa e Inovação do

Estado de Santa Catarina. Process number 1459/2012. 